\title{
Achieving the BTC Qualification
}

A. Munro, Professor and Head, Department of Psychiatry, Dalhousie University, W. O. McCormick, Professor and Director of Postgraduate Psychiatric Education, Dalhousie University and D. W. ARCHIBALD, Administrator of Psychiatric Mental Health Services, Province of Novia Scotia

Since 1984, Nova Scotia has had a programme to bring a small number of senior trainees in psychiatry from Britain or Ireland to undertake one year of clinical work plus continuing medical education here. This programme is sponsored by the Nova Scotia Provincial Department of Health in collaboration with the Dalhousie University Department of Psychiatry.

One of us (D.W.A) is Administrator of Mental Health Services for Nova Scotia, responsible for the supervision of 13 mental health centres around the province, and including a small psychiatric hospital (of 100 beds) on Cape Breton Island and the larger Nova Scotia Psychiatric Hospital (of 350 beds) in Dartmouth, near Halifax. These multidisciplinary mental health centres are strategically placed to provide primary and secondary psychiatric care across the whole province. The other two authors work in the teaching hospital system in the Metro Halifax area and are involved in secondary and tertiary psychiatric care, in addition to all the academic activities of a university clinical department. In recent years there has been a conscious attempt to begin integrating the various levels of psychiatric care into a province-wide network.

Outside the teaching hospitals, recruitment of psychiatrists has not always been satisfactory and we have considered various methods of attracting well-qualified individuals to the province, since the output of trained psychiatrists from Dalhousie University has never been sufficient to fill all the available positions. Unfortunately, medical immigration into Canada is now very restricted and this has virtually prevented recruitment from other countries of late.

In discussion with academic colleagues in Britain and Ireland we realised that, in recent years, something of a promotion bottleneck has developed there, with some senior registrars having to wait for considerable periods before obtaining promotion to consultant. In these circumstances, a candidate with extra qualifications or experience may be at an advantage, and it occurred to us that we might put our two situations in conjunction and come up with advantages both for the senior trainees and for Nova Scotia. In the old days, the BTA (Been to America) qualifcation was held in high esteem: perhaps nowadays we might be able to offer an equally valuable BTC (been to Canada)?

We therefore devised our programme which is principally open to registrars and senior registrars from Britain or Ireland who have the MRCPsych, and preferably four years of training. Lately, we have widened our scope and have had a Norwegian psychiatrist with us for a year. Individuals can come to Nova Scotia for one year to work in one of the mental health centres as the equivalent of a junior consultant. Their psychiatric practice is varied and interesting, and there is usually an opportunity to experience urban and rural aspects of practice, and to collaborate with other mental health professionals in a therapeutic team. Clinical work takes up four days a week (for which, currently, a salary of $\$ 56,800$ Canadian per annum is paid): the fifth day is given over to continuing medical education at Dalhousie University. The CME arrangement is made flexible so that it can be taken one day a week or as a consolidated block of time. In Canadian terms, the year cannnot be officially recognised as part of specialty training, but in practice it offers a year of very solid clinical experience with good quality postgraduate training and opportunity for some conjoint learning with our own residents. So far, 11 young psychiatrists have taken part and a number are presently awaiting their turn. One of our first four candidates did not find the situation congenial and quickly returned home: the others have enjoyed their experience and several of them have elected to remain in Canada for the present, rather than return to Britain or Ireland. We do, however, stress that trainees should try to obtain leave, rather than resign their training posts, since permanent immigration, though possible, is now indeed a difficult and strenuous exercise.

Psychiatry in Nova Scotia is not very different from British psychiatry. There is a somewhat heavier emphasis on psychotherapy, and we increasingly utilise DSM III as our diagnostic guide, but in general a British or Irish graduate will find little here that is unfamiliar. A provincial medical insurance scheme covers the majority of medical costs, so that virtually universal health care access is available. Academic psychiatry at Dalhousie University is similar in many ways to academic psychiatry in the British Isles, and standards are well up to these in other parts of Canada. A registrar or senior registrar who spends a year here and uses his or her opportunities well can return to the the promotion race with considerably enhanced knowledge and experience.

\section{The province}

By Canadian standards, Nova Scotia is a small province, being slightly less in area than Scotland. It is a beautiful region, largely rural and with much unspoiled countryside. Its total population is 850,000 and Halifax, the capital, with its metropolitan area, has 280,000 people. Although the British usually think of Canada as being somewhere up there', Halifax is, in fact on the same latitude as northern Italy and we therefore enjoy a southern European sun. The climate is not very different from Britain's but the winters are somewhat colder and the summers and autumns are consistently warmer and less capricious. It is well-connected by air, road and rail to other parts of Canada and to the north-eastern United States. 
Nova Scotia, New Brunswick and Prince Edward Island make up the Maritime Region of Canada: add Newfoundland, and you have the Atlantic Region. Dalhousie Medical School serves the whole of the Maritime Region, and Dalhousie University is one of the more venerable and better-known in Canada.

\section{Prospects of immigration to Canada}

At present, Canada regards itself as well-supplied with physicians, but psychiatry remains a shortage specialty. Until lately, it was usually possible to aid immigration for suitably trained psychiatrists but even there the situation has become all but impossible. Even if one gains a foothold, there are many hurdles to clear; the Evaluating Examination of the Medical Council of Canada (MCCE), the Licentiate Examination of the Medical Council of Canada (LMCC, the equivalent of MB Finals), and the two-part specialty examination of the Royal College of Physicians of Canada all have to be passed. (Unfortunately, the MRCPsych is not recognised here as a specialty qualification though appropriate training is accepted in lieu of Canadian training). Provincial licensing authorities set their own criteria to a considerable extent, and senior trainees coming to our programme are given temporary licences lasting only for the year they undertake. Anyone considering formal immigration also has to go through a daunting series of procedures before being awarded Landed Immigrant status. Increasingly nowadays, examinations, licensing and immigration are being made dependent on each other, and our authorities sometimes seem to go out of their way to be obstructive to the aspiring entrant. It should be added that our licensing authority has recently decreed that the MCC Evaluating Examination be passed in advance by everyone who wishes to enter the programme.

Having said all these discouraging things, our programme does provide one of the few opportunities today for British and Irish graduates to obtain a taste of psychiatric practice under favourable conditions in Canada. (In some provinces, enticing advertisements aimed at foreign graduates are trying to attract psychiatrists to underserviced areas in which Canadians will not consider working). We cannot promise a sure pathway to immigration for those who might be interested in this, and that is why we advise people to take leave from their training posts rather than resign from them. We don't want you to count your chickens after your bridges are burned. However, if someone has worked out well and wishes to stay, we will use our help and influence in assisting with the necessary arrangements for immigration.

\section{If any senior trainees are interested}

We are now filling our provincial psychiatric posts more rapidly than in the past, so this programme may be timelimited since it depends on funding which would otherwise pay for conventional staff psychiatrist positions. If any senior trainee with the MRCPsych is interested in the prospect of a year in Nova Scotia, he or she should first discuss the idea with his/her Postgraduate Director and/or Head of Academic Department. Then, anyone wishing to pursue the process further should write for information to:

Dr Douglas W. Archibald

Administrator, Psychiatric Mental Health Services

Province of Nova Scotia

PO Box 488

Halifax, Nova Scotia B3J 2R8 Canada

Of course, to some extent this is a recruiting pitch by us, but we think that it is one that offers some very valuable options to interested individuals. You can spend a well-paid year polishing up your experience and knowledge and return with your 'BTC'. On the other hand, if you have a mind to move to Canada, this can help you weigh up your options and, if you are enterprising, you can begin taking the appropriate steps to start the migration process.

Incidentally, the mental health centre to which you would be attached will give some practical help about housing, etc, and it is perfectly possible to find accommodation for a spouse and family at reasonable rentals. However, you will be expected to pay rent and other normal expenses, and find the cost of your return journey to and from Canada. With the salary you receive, you can do these things, have a good holiday in Canada during your stay, enjoy a pleasant standard of living, and still return home with some change in your pocket.

\section{Footnote}

Since the programme has worked so well in Nova Scotia, the province of New Brunswick is currently considering the possibility of negotiating a similar arrangement. Two of the authors (A.M. and W.O.McC.) will be involved with this and can provide information as the plan develops.

\section{£750,000 Endowment to help Drug Addicts}

The J. Paul Getty Jr Charitable Trust has announced its intention to support work being carried out at the Institute of Psychiatry on the prevention of drug addiction, and on the care and rehabilitation of addicts. A sum of $\$ 750,000$ is to be paid to the Institute over the next five years.

Accepting the endowment on behalf of the Institute, Professor Griffith Edwards, the Professor of Addiction Behaviour, said "The Institute is greatly favoured in being chosen for such generous and timely support. The explosive increase in the misuse of all kinds of substances in recent years is widely accepted as one of the greatest threats to our national wellbeing. Our fundamental aim at the Institute is to reduce by all means at our disposal the death, suffering and social deprivation now being caused by the misuse of drugs".

The endowment will enable the Institute to provide a more permanent core team for work in this vital area, which is currently dependent on short-term grant support. 